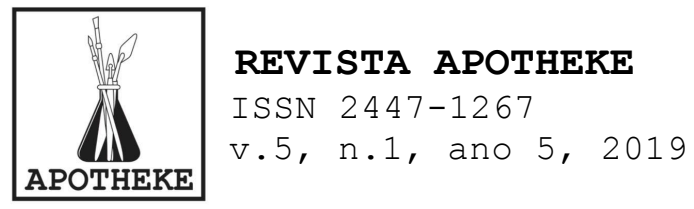

\title{
Cy Twombly: Rabiscos, Manchas e Borrões.
}

\author{
Flávia de Lima Duzzo
}

\begin{abstract}
RESUMO: O artigo discorre sobre algumas das características que compõem o desenho e a pintura, como essas duas linguagens relacionam-se e onde se distinguem. O texto apoia-se nos escritos de Roland Barthes em que o filósofo analisa as obras de Cy Twombly realizadas no período de 1961 a 1979 e no ensaio de Walter Benjamin que data de 1917, no qual o autor apresenta, de maneira disjuntiva, os elementos da pintura e os do desenho. As duas reflexões examinam aspectos como a mancha, o suporte, o traço, inscrições e grafismos. Barthes comenta sobre elementos que estão presentes nas pinturas de Twombly que poderiam ser tidos como exclusivos do vocabulário do desenho. Com base nas abordagens apresentadas pelos dois filósofos, pretende-se promover um debate sobre essas duas linguagens, problematizar as especificidades de cada uma bem como refletir como essas características mostram-se na arte mais recente.
\end{abstract}

PALAVRAS-CHAVE: Desenho. Pintura. Superfície.

ABSTRACT: The paper discuss some of the characteristics that compose the draw and the painting; how these two languages relate to each other and where they differ. The text is based on the writings of the philosopher Roland Barthes, where he analyses Cy Twombly work from 1961 to 1979 , and is based on Walter Benjamin essay of 1917, that presents the elements of painting and drawing in a disjunctive way. Both reflections explore aspects like the stain, the support, the stroke, inscriptions and graphisms. Barthes comments on elements that are present in Twombly's paintings that could be considered exclusive in the drawing collection. From the approaches presented by the philosophers it is intended to promote a debate about these two languages, to discuss about the specificities of each one, and to reflect about how those characteristics are showed in the more recent art.

KEYWORDS: Drawing, Painting, Surface.

o que torna o traço o grafismo tão marcante na obra de Cy Twombly ${ }^{1}$ ? Sabemos que sua pintura não se compõe apenas de riscos e inscrições gráficas. Sua obra apresenta uma variada gama no tratamento dos diferentes elementos que formam a

1 Artista americano, nascido em Lexington, Virginia (1928 - 2011), estudou na School of the Museum of Fine Arts, Boston (1947-49), Art Students League, New York (1950-51) e em Black Mountain College, North Carolina (1951-52). Sua obra compõe-se de pinturas, desenhos, esculturas e fotografias. Em 1957, muda-se definitivamente para a Itália, passa a ter contato com a cultura do Mediterrâneo, o que irá refletir-se decisivamente em sua obra. São recorrentes em suas obras temas referentes à mitologia grega e romana, literatura e história ocidental. 


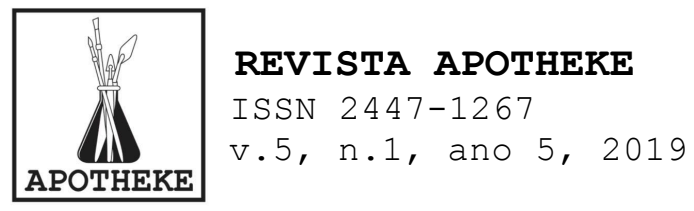

linguagem do desenho e da pintura. Como explicar a crescente atração que seus traços exercem sobre a atenção de teóricos e artistas ligados prioritariamente ao desenho? A obra de CY Twombly pode ser abordada por várias vias de análise justamente por apresentar diversos aspectos que a distinguem. As manchas, as grandes dimensões, a presença do gesto que imprime velocidade a seus trabalhos são, entre outras, fortes características do seu fazer artístico.

o presente artigo propõe desenvolver um pensamento sobre a linha do desenho com base nos aportes teóricos de Roland Barthes ${ }^{2}$ sobre 0 grafismo de Cy Twombly apresentados nos textos: Cy Twombly ou nom multa sed multon e Sabedoria da arte $^{3}$. Esta reflexão abordará também a conceituação apresentada por Walter Benjamin 4 no ensaio Sobre a Pintura: Sinal ou Mancha, do ano de 1917, no qual discute os limites e as especificidades das linguagens do desenho e da pintura.

Roland Barthes analisa, nos seus dois ensaios, vários aspectos das obras de Cy Twombly, realizadas no período entre 1961 e 1979, aproximadamente. Questões como a escrita e sua alusão à caligrafia, a presença da mancha que traduz o gesto do artista e o envolvimento do seu corpo na fatura da obra serão aqui estudados.

Barthes aponta a maneira como considera que Cy Twombly enuncia a questão do traço. Refere-se primeiramente ao que chama de rabiscos em trabalhos como Olympia, Free Wheeler ou The Geeks, nos quais o artista emprega lápis grafite, lápis de cor, giz de cera e tinta de parede à base de óleo sobre tela. Barthes considera tais grafismos

\footnotetext{
2 Escritor, sociólogo, crítico literário, semiólogo e filósofo francês.

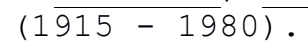

3 Esses ensaios foram originalmente publicados em: Cy Twombly: catalogue raisonnné des ouvres sur papier, 1973-1976. Yvon Lambert, Ed. Multipha Milão, 1979.

4 Ensaísta, crítico literário, tradutor, filósofo e sociólogo alemão $(1 \overline{892-1940)}$.
} 


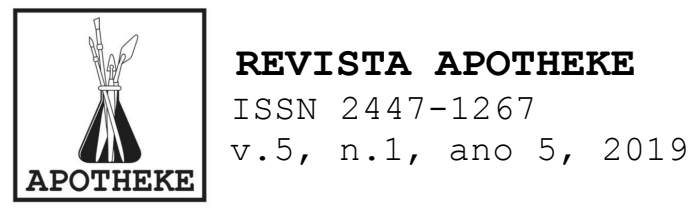

[...] como um gesto de vaivém, por vezes obsessivo, como se o artista manejasse as linhas que ele desenha como alguém que se aborrece em uma reunião e enche de rabiscos aparentemente insignificantes um canto do papel que está na sua frente. (BARTHES, 1982, p.154).

É interessante pensarmos a respeito da intensidade e amplitude do gesto que Twombly investe nas inscrições gráficas que realiza em superfícies de grandes dimensões, que costumam variar entre 200 e 300 cm, aproximadamente. As dimensões de suas pinturas fazem com que os grafismos potencializem-se através da escala; estes adquirem medidas humanas que nos confrontam num corpo a corpo. O impacto é de outra ordem se comparados com pequenos desenhos ou rabiscos que realizamos distraidamente em folhas de cadernos ou blocos de notas aos quais se refere Barthes.

Percebe-se que o tipo de grafismo que Twombly preza é aquele resultante de um gesto despojado de destreza. De acordo com o artista:

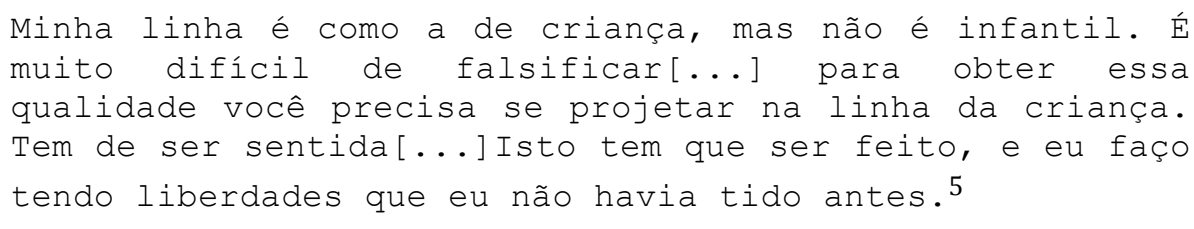

Os gestos que o artista aplica na inscrição de seus grafismos lembram o movimento que fazemos na escrita cursiva. Porém, na escrita formal, realizamos pequenos movimentos com a mão, gestos contidos que têm intenção de alcançar uma legibilidade. Juntamente com os rabiscos, o artista introduz diversas vezes a escrita em seus trabalhos: letras, palavras, nomes. Vale-se de uma caligrafia canhestra que se assemelha às garatujas infantis. Porém, segundo Barthes, diferentemente de

\footnotetext{
5 "My line is childlike but not childish. It is very difficult to fake... to get that quality you need to project yourself into the child's line. It has to be felt... I work in waves, because I'm impatient. Because of a certain physicality, of lack of breath from standing. It has to be done and I do take liberties I wouldn't have taken before." Disponível em: http://www.artquotes.net/masters/cy-twombly/index.htm. Acesso em: 3 ago. 2012.
} 


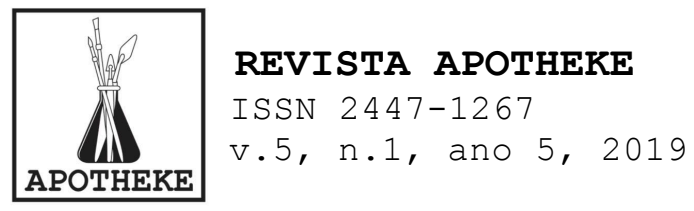

uma criança que se esforça para atingir a inteligibilidade da escrita adulta, Twombly afasta-se desses códigos, o artista não se interessa pela "boa caligrafia".

A representação dos signos gráficos utilizados por Twombly não está desprovida de conteúdo semântico, a potência do traço e do que está inscrito não podem ser dissociados. Encontram-se amalgamados, resultam da articulação entre a intenção e ação do artista para a sua concretização. O pintor inscreve em suas telas nomes ligados à mitologia, à história mediterrânea antiga e à poesia épica. Na visão de Barthes, essas obras têm a propriedade de evocação no sentido de tornar presente o que enuncia.

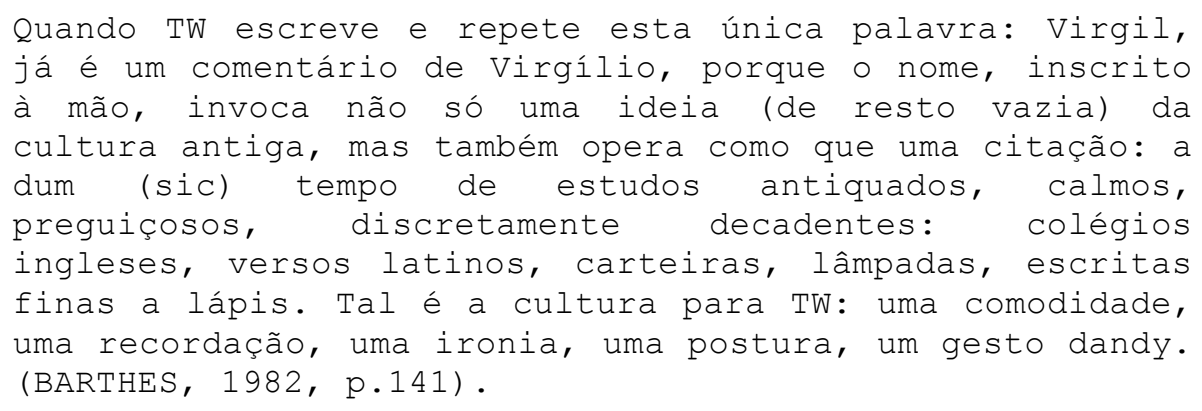

A obra de Cy Twombly tornou-se mais conhecida pelas grandes dimensões de suas telas, pelos grafismos, pela liberdade de sua caligrafia, pelos campos de cor em tons esbranquiçados. Para melhor pontuar esta reflexão, analisarei uma obra específica que apresenta muitas das características mais representativas de suas pinturas. A tela The Italians (Fig.1) foi pintada em janeiro de 1961, período em que Cy Twombly viveu em Roma. Essa pintura mede $199.5 \mathrm{~cm}$ x $259.6 \mathrm{~cm}$, e o material empregado é tinta a óleo, lápis e crayon sobre tela. No site do museu de Arte Moderna de Nova York (MOMA) ${ }^{6}$, encontra-se a seguinte descrição dessa obra:

\footnotetext{
6 Trago essa informação com o fim de complementar com dados escritos a percepção da imagem a que geralmente temos acesso somente por meio de reproduções.
} 


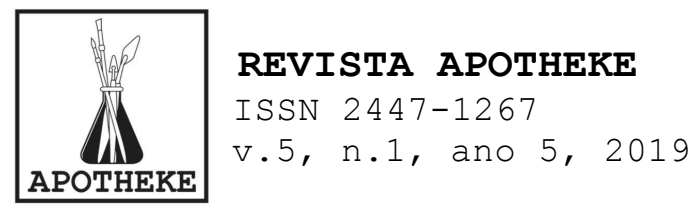

Selvagem, rabiscado, com marcas que se parecem com
graffiti e que energizam a expansiva superficie branca
de The Italians, revelando a alegria sensual do artista
na manipulação de seus meios. A explosão de signos,
ironicamente, não se dá sem ordem ou clareza: a fricção
do carvão no lado esquerdo da tela revela a marca do
chassis que está por baixo, um coraça vermelho pode ser
visto ao fundo, e 'Roma' é escrito justo abaixo da
assinatura na parte superior à direita.

A descrição acima aproxima-nos de detalhes dessa obra que se encontram estreitamente ligados ao procedimento e à consequente poética construída pelo artista. A despreocupação do gesto fica salientada quando se tem conhecimento, por exemplo, da marca que o crayon deixa na tela quando é friccionado sobre o chassi. A despreocupação está ligada à liberdade, não à displicência ou descaso; percebe-se nesta, como em tantas outras telas de Twombly, um cuidado na composição, uma lógica interna no trabalho. Diversos elementos, procedimentos, materiais e diferentes intensidades de gesto são colocados na tela, seguindo uma ordem muito particular. Os desenhos feitos a lápis com gestos velozes, ora produzem rabiscos, ora configuram formas, letras e palavras. Parece haver nesse trabalho uma urgência que, ao mesmo tempo, é apaziguadora. A linha acelera-se, traz movimento à cena; a cor confere um ambiente calmo e rarefeito que recebe os grafismos.

\footnotetext{
7 Wild, scribbled, graffiti-like marks energize the expansive white surface of The Italians, revealing the artist's sensuous joy in manipulating his medium. The explosion of signs, ironically, is not without order or clarity: the rubbing of charcoal on the far left side of the canvas reveals the stretcher bar beneath it, a red heart can be seen at the bottom, and "roma" is written just beneath the artist's signature at the top right. MOMA: Disponivel em:http://www.moma.org/collection/object.php?object_id=79852. Acesso em:3 ago. 2012. Tradução da autora.
} 

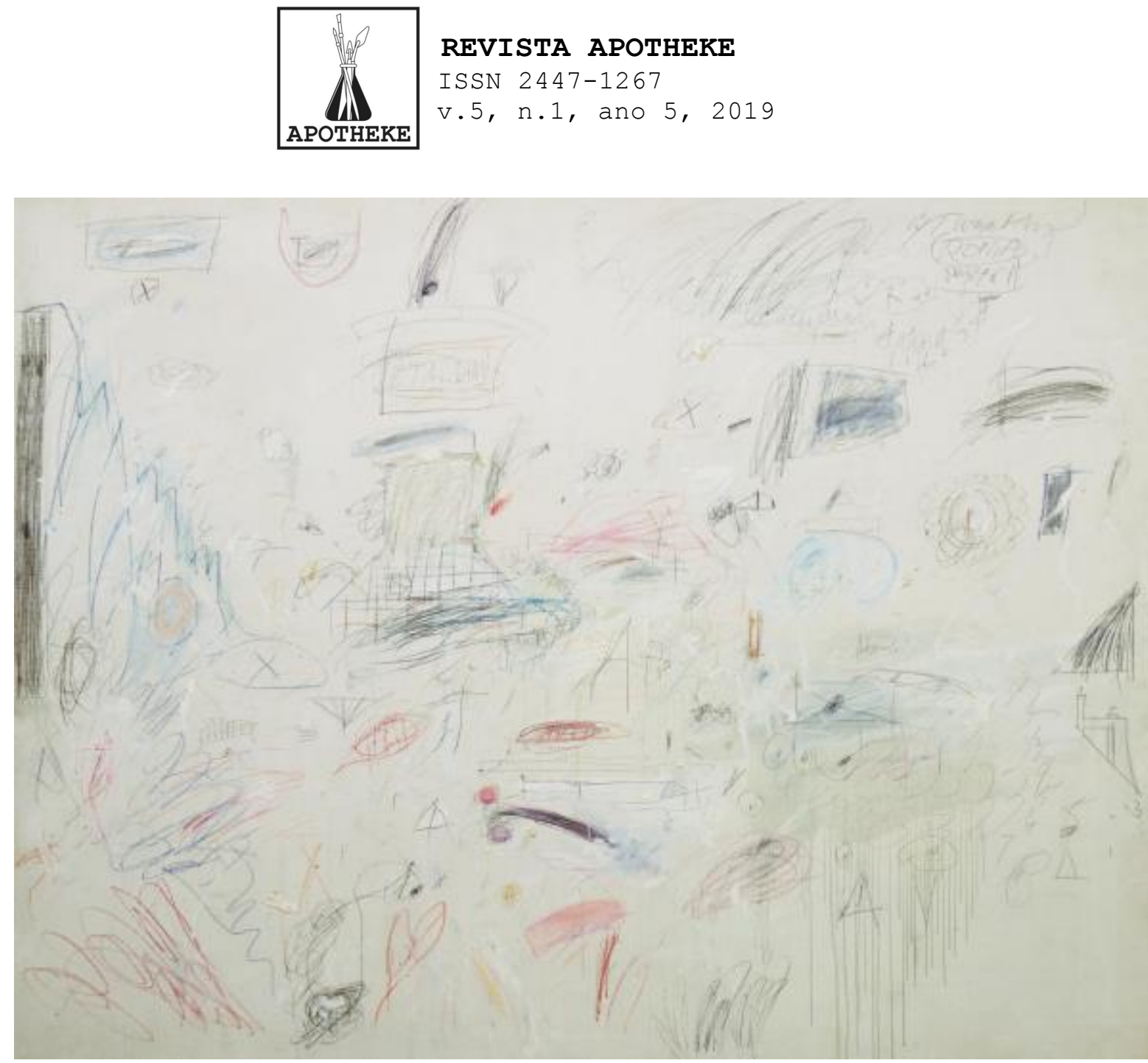

Fig.1 Cy Towmbly. The Italians, 1961. Óleo, lápis e crayon sobre tela. $199.5 \times 259.6 \mathrm{~cm}$

Walter Benjamin, por sua vez, faz uma diferenciação do que seria sinal e mancha. Benjamin apresenta um pensamento disjuntivo em que o sinal estaria exclusivamente ligado ao repertório e elementos do desenho, enquanto a mancha, aos da pintura. Apresentando as duas linguagens sempre uma em oposição à outra, afirma: "a primeira diferença fundamental reside no fato de o sinal ser uma marca que se imprime, enquanto a mancha, pelo contrário, é algo que se manifesta" (BENJAMIN, 2012).

Barthes, no desenrolar de seu pensamento, argumenta que a arte de Twombly dá a ver não o que ele representa, mas os materiais que utiliza: a verdade do lápis, a porosidade do papel, a fluidez ou empaste da tinta. E nessa cumplicidade 


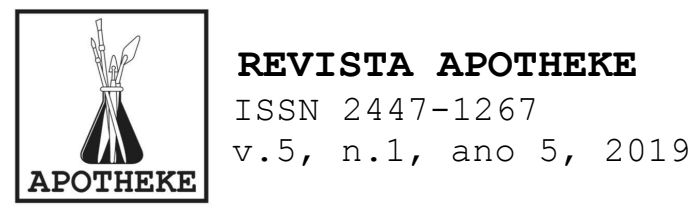

entre artista e matéria, Barthes percebe que é pela sutil insinuação do material que Twombly traduz a essência deste.

\begin{abstract}
Pode-se imaginar que, para falar do lápis, é preciso pressioná-lo contra o papel, reforçar-lhe a aparência, torná-lo espesso, intensamente negro. Twombly pensa o contrário: é contendo a pressão da matéria, deixando-a pousar-se distraidamente para que o seu grão se disperse um pouco, que a ela, a matéria, mostrará sua essência, e nos dará a certeza do seu verdadeiro nome: é lápis. (BARTHES, 1996, p.92).
\end{abstract}

Diante de uma pintura de Cy Twombly, podemos sentir sua pulsação e intensidade, enfim, várias experiências significativas podem ocorrer nesse encontro. Esses tantos atributos da obra do artista estariam ligados também à relação de respeito e à ênfase que o artista dá às propriedades materiais de seus meios? Barthes deixa claro a sua convicção quando afirma:

A arte de Twombly consiste em nos fazer ver as coisas: não as que ele representa (esse é outro problema), mas as que ele manipula: alguns rabiscos a lápis, esse papel quadriculado, um toque de cor-de-rosa, essa mancha marrom. (BARTHES, 1996, p.92).

Parece haver uma escuta por parte do artista com relação às necessidades dos trabalhos. Penso que a intimidade do artista com seus materiais e a não hierarquização destes atribui potência à obra.

Barthes salienta que os instrumentos utilizados por Cy Twombly deixam de ser instrumentos e passam a existir como um fato em sua pintura. Twombly trata-os não como utensílios que estariam servindo a um propósito, mas como uma matéria absoluta.

- poder demiúrgico do pintor é o de fazer existir o material como matéria; mesmo que algum sentido venha da tela, o lápis e a cor permanecem 'coisas', substâncias inflexíveis, cuja obstinação de estar ali' não pode ser destruída por nada (nenhum sentido posterior). (BARTHES, $1996, \mathrm{p} .92$ ).

Barthes discorre sobre o gesto que Twombly aplica na configuração de seu traço: aquele que produz a mancha. 


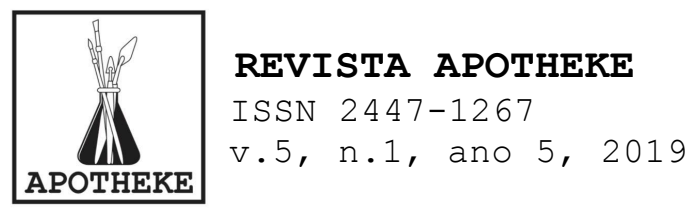

Twombly dirige suas manchas, arrasta-as, como se usasse
os seus dedos; seu corpo está lá, próximo da tela, não
através de uma projeção, mas, por assim dizer, através
de um toque, sempre leve [...] (BARTHES, 1982, p. 154).

As telas apresentam cores atenuadas que Barthes avalia estarem mais próximas do que chamamos mácula do que propriamente mancha. Máculas são manchas que estão relacionadas ao corpo, brotam na pele; do mesmo modo, as máculas de Cy Twombly estariam aflorando da superfície de suas telas. Poderíamos pensar nessas telas como pele humana, como um organismo vivo.

Essa mesma percepção com relação à mancha está presente em Benjamin. Segundo o filósofo alemão (2012, p.4), a mancha aparece, sobretudo, naquilo que é vivo, como na epiderme, o que contribui para a sua frequente associação à culpa manifestada através do rubor; ou à inocência se pensarmos nas chagas de Cristo. Percebe-se que ambas as visões, de Barthes e de Benjamin, consideram a mancha como algo que aflora, que emerge em uma dada superfície.

Benjamin, ao relacionar o sinal exclusivamente ao campo do desenho e a mancha ao da pintura, considera a técnica da aquarela como a única possibilidade de união entre esses dois meios num mesmo espaço, na ocupação de uma mesma superfície.

O único caso em que a linha e a cor se encontram é o da aguarela (sic), em que os contornos do lápis são visíveis e a cor é aplicada em transparência. Neste caso, o fundo se conserva apesar do colorido. (BENJAMIN, 2012, p.5)

Devido à transparência da tinta, o sinal continua aparecendo como tal e relacionando-se com o fundo e, ao mesmo tempo, há o encobrimento total da superfície do papel, o que garante a permanência da mancha.

O signo gráfico do desenho caracteriza-se pelo seu contraste com a superfície e, segundo o filósofo, a linha, ao inscrever-se sobre uma superfície, considera o fundo na medida 


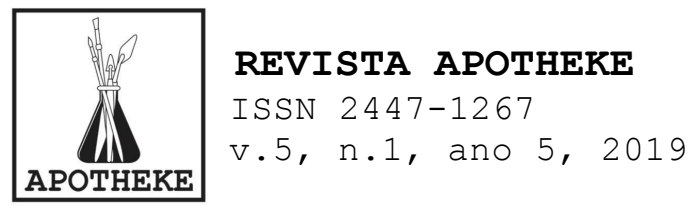

em que não o encobre. Benjamin afirma que a linha marca a superfície em que se coloca e com isso faz com que o fundo esteja subordinado a si mesmo. E ainda: "uma linha desenhada também só existe sobre este fundo, de tal modo que, por exemplo, um desenho que cobrisse totalmente seu fundo deixaria de o ser" (BENJAMIN, 2012, p.3).

Benjamin considera que a mancha não reconhece o fundo, uma vez que se deposita sobre toda a área da superfície em que se coloca. A mancha se dá por si só, dispensa o uso da linha de contorno na criação de formas. Em sua visão, seria por meio da composição que um quadro alcançaria uma nomeação, sairia da indiferenciação da mancha, do âmbito do irrepresentável e passaria a relacionar-se com uma coisa que ele próprio não é; com o que é transcendente à mancha. Algo no quadro passa a acontecer que não apenas o medium da mancha. E, nessa operação, Benjamin aponta para a autonomia da composição, pois não necessita recorrer à linha para alcançar a diferenciação de suas áreas e de seus elementos. Nos trabalhos de Twombly, entretanto, vemos que sinal e mancha podem habitar um mesmo sistema. 8

Em alguns trabalhos de Twombly, Barthes menciona haver um gesto que gera o que ele irá denominar de borrões. ${ }^{9}$

É uma dialética sutil: o artista finge 'estragar' uma parte da tela e querer apagá-la. Mas ele de novo estraga a emenda e essas duas falhas sobrepostas produzem uma espécie de palimpsesto: elas dão à tela a profundidade de um céu em que nuvens passam umas pelas outras sem se encobrirem. (BARTHES, 1996, p.93).

8 Creio que pode ser um exercício interessante tentar olhar um trabalho contemporâneo através de enfoques que foram elaborados em tempos que estão muito distantes, tentando encontrar dissonâncias ou afinidades. O artista contemporâneo que conhece bem as especificidades de cada meio consegue articular de maneira mais consistente os cruzamentos de linguagens em seus trabalhos.

$9 \mathrm{Na}$ tradução portuguesa do livro O Obvio e o Obtuso o termo utilizado é sujidade. Opto aqui por utilizar o termo borrão usado na tradução brasileira que se encontra no catálogo da XXIII Bienal de São Paulo. 


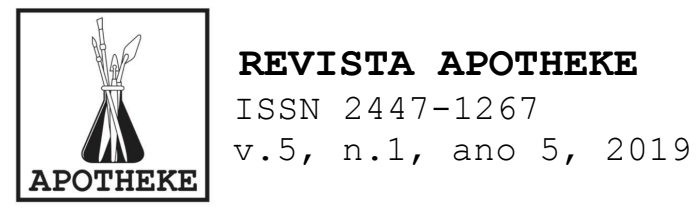

Os borrões podem ser entendidos como uma honestidade do artista, que não esconde as mudanças de rumo que dá à sua obra.

Sabe-se que na pintura renascentista, o ideal de uma grande obra de arte era que os vestígios de sua feitura não ficassem aparentes. Como se a imagem fosse simplesmente uma aparição que não tivesse passado pela mão do pintor que utilizara pincel e tinta em sua execução. Em algumas pinturas, no entanto, as camadas de tinta, com o passar do tempo, foram ficando mais transparentes, deixando que algumas imagens subjacentes à tela se tornassem visíveis. Alteração de formas e composição, enfim, as mudanças de ideia do pintor podem tornar-se visíveis, o que, em pintura é chamado de pentimento. Pentimento (pentimenti) é uma palavra de origem italiana e está ligada à ideia de arrependimento. Cy Twombly expõe seus arrependimentos; não necessitamos da ação do tempo em suas obras para podermos acessar às suas dúvidas e tomadas de decisões. Ele pinta, apaga, volta a pintar e riscar, deixa as marcas da borracha aparentes, enfim, deixa os rastros das suas idas e vindas, o que compõe de forma determinante a poética de sua obra.

\footnotetext{
[...] isso apaga-se pouco a pouco, esbate-se conservando a delicada sujidade da apagadela da borracha; a mão traçou qualquer coisa como uma flor e depois pôs-se a divagar sobre este traço: a flor foi escrita, em seguida desescrita (sic), mas os dois movimentos ficam vagamente sobre-imprimidos. [...]encontram-se reunidos, cada um tendendo a apagar os outros, mas dir-se-ia com o fim de dar a ler este apagamento: verdadeira filosofia do tempo. (BARTHES, 1982, p.143).
}

Os acidentes de percurso vão sendo incorporados à obra provocando a soma de camadas e, desse modo, acrescentam-lhe potência. Esse caráter de palimpsesto10 traz maior densidade ao

10 Gerard Genette (1930), crítico literário francês e teórico da literatura, em seu livro Palimpsestos: a literatura de segunda 


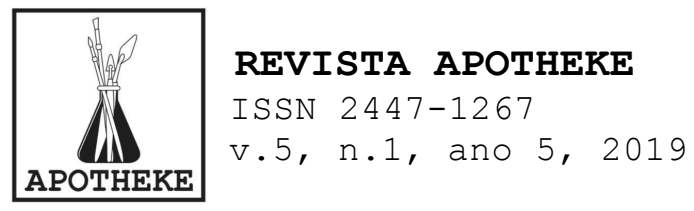

trabalho; podemos escavá-lo com os olhos e aproximarmo-nos ainda mais do que teria sido o seu processo de construção e elaboração, um procedimento arqueológico. As escavações realizadas pelos arqueólogos buscam pistas de uma existência desconhecida. De algo que pertenceu à outra época e que possivelmente está extinto. A arqueologia, de certa forma, lida com a memória; busca um passado e o traz para o presente como intuito de interpretá-lo e também conhecer algo que possua um caráter de ineditismo. A relação do espectador diante de uma tela de Cy Twombly mantém certa semelhança com a atitude do arqueólogo. Temos uma curiosidade de encontrar um sentido oculto, algo soterrado, que não esteja na superfície. Entretanto, a soma de seus passados, de suas etapas de feitura atualiza-se na obra acabada. Penso que seja através da "transparência" das atitudes do pintor, por sua ética com relação a seus procedimentos, que acessamos a totalidade da obra; suas tantas camadas de sobreposição não apenas de matéria, mas também de sensibilidade, cognição e sentidos.

Em certa medida, palimpsesto ${ }^{11}$ e pentimento apresentam uma proximidade em suas conceituações; o primeiro está ligado à escrita, e o segundo, à imagem. O que difere na sobreposição a que estão submetidos é que no pergaminho sabe-se de antemão que o que nele for escrito apagar-se-á para dar lugar à outra mensagem. Quando o pentimento acontece em uma tela, vem acompanhado de um caráter imprevisto e indesejável, principalmente porque, quando esse acidente manifesta-se, fica patente a manualidade que deu origem àquela imagem. Nossos conhecimentos sobre a história da arte e o contato com alguns

mão discorre sobre o que considera ser o mais importante objeto de estudo da poética: intertextos, discorrendo entre outros temas, sobre a transcendência textual do texto.

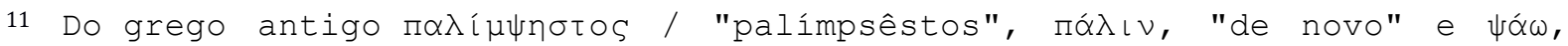
"riscar", ou seja, "riscar de novo". Trata-se de um pergaminho que na Idade média era reutilizado através da raspagem devido a seu alto preço. Disponível em: http://pt.wikipedia.org/wiki/Palimpsesto. Acesso em: 27 jul. 2012 . 


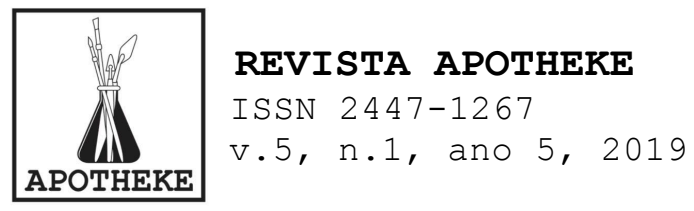

preceitos da arte contemporânea, muitas vezes, levam-nos a encontrar uma beleza nessas pinturas cujas imagens se sobressaem umas das outras. É como se ficasse revelado, através da imagem, um mistério, um segredo que os acompanhasse. Nesse sentido, porém, torno a pensar na ideia de que Twombly não esconde truques em suas obras.

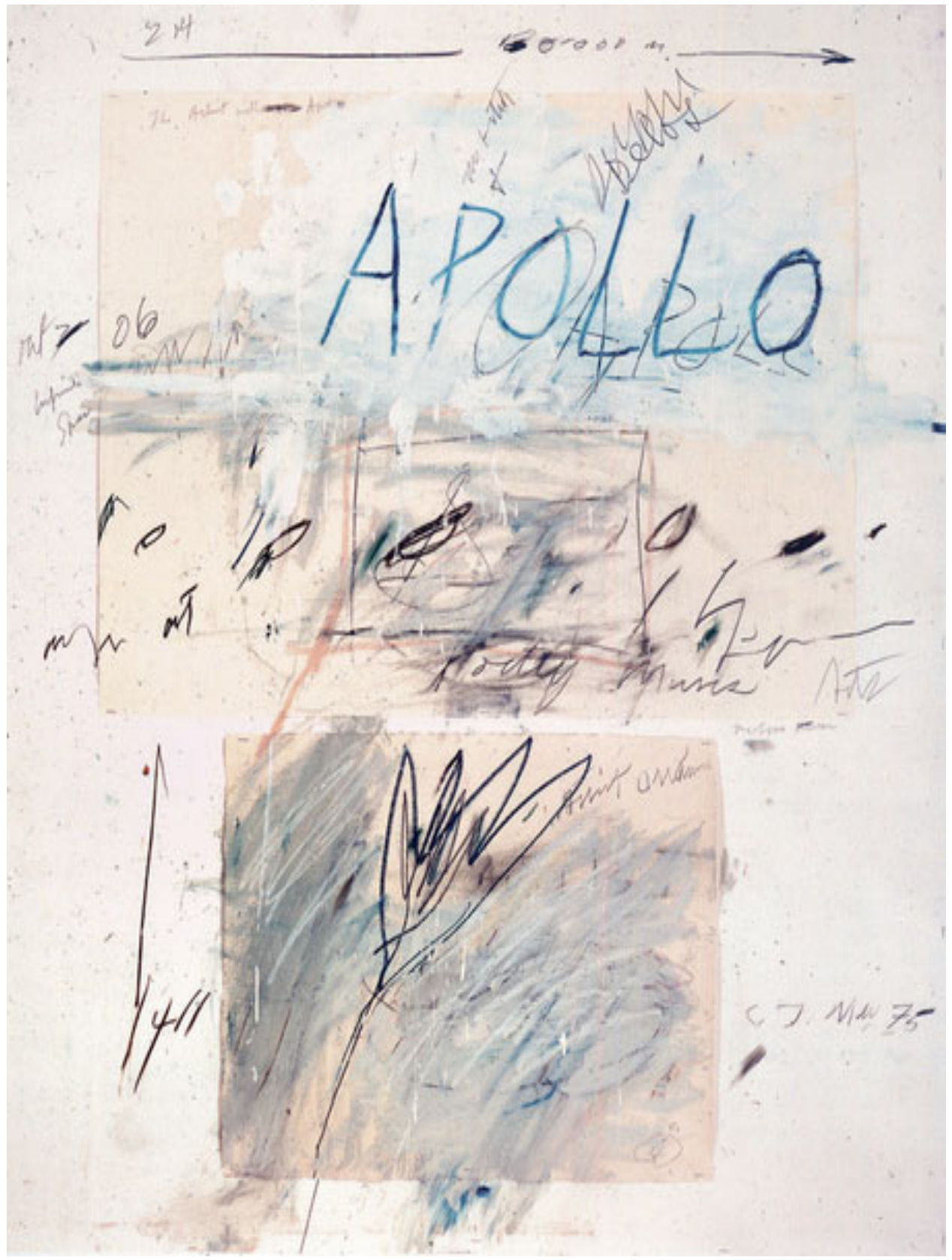

Fig. 2 Cy Twombly. Apollo, 1975. Tinta a óleo, giz de cera,lápis e colagem sobre papel. $142 \times 128 \mathrm{~cm}$ 


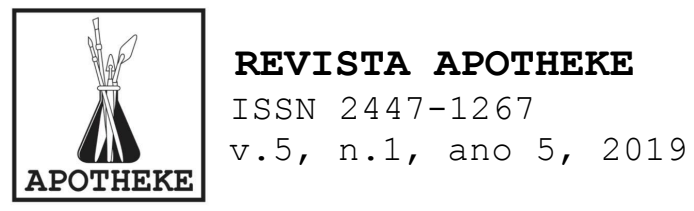

A partir do ano de 1975, Twombly começa a agregar combinações de texto e imagens em seus trabalhos, integrando esses elementos com linhas escritas, desenhos e cores. Apollo (Fig. 2), Venus (Fig. 3) e Mars and the Artist são obras sobre papel, nas quais o artista utiliza materiais como tinta de parede, caneta e tinta a óleo, fazendo também uso da colagem.

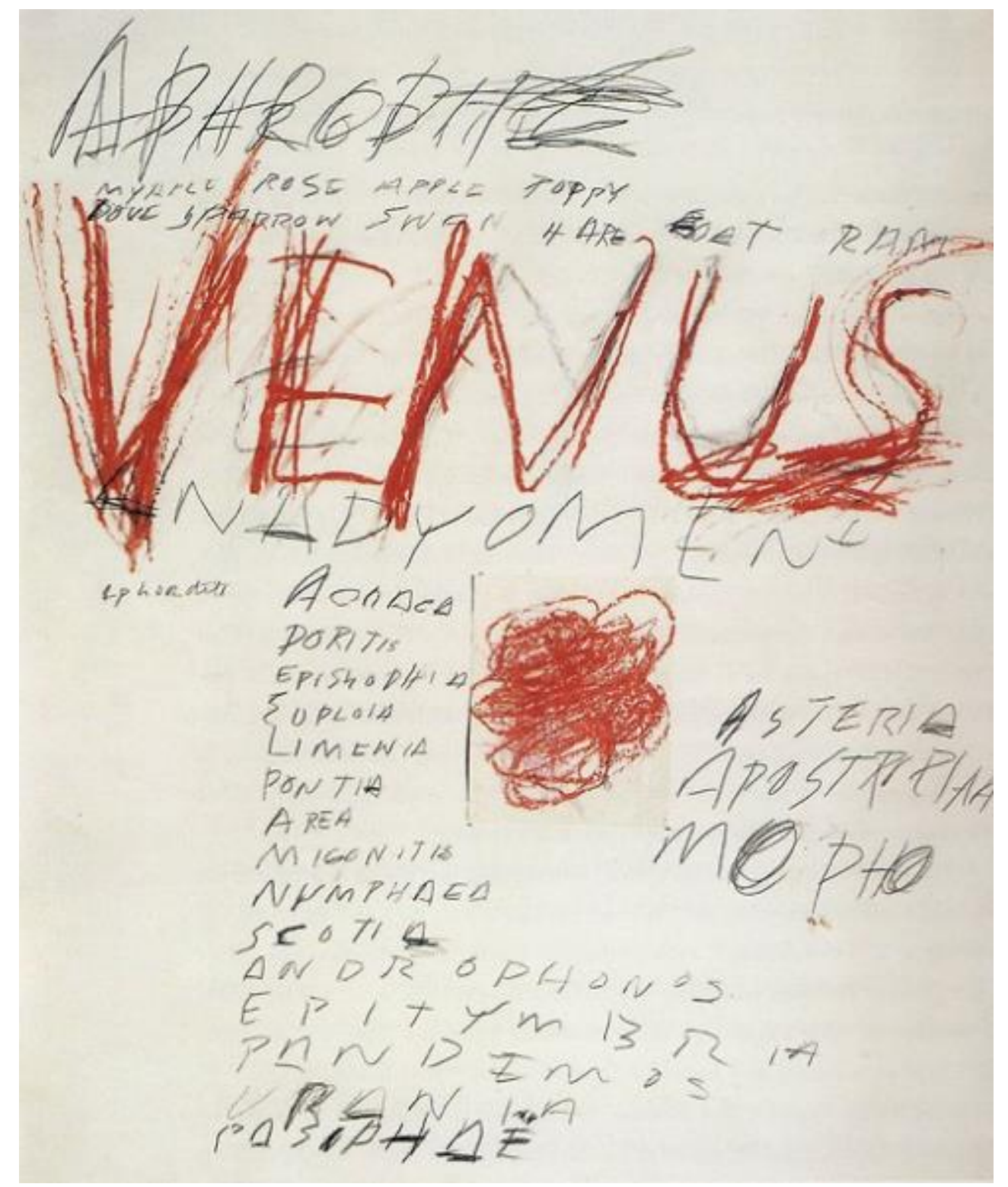

Fig. 3 Cy Twombly. Venus, 1975. Bastão a óleo, grafite e colagem sobre papel. 150 × $137 \mathrm{~cm}$

Ao olhar a obra Venus, minha visão fixa-se primeira e instantaneamente no traço. Dentre os elementos inseridos na 


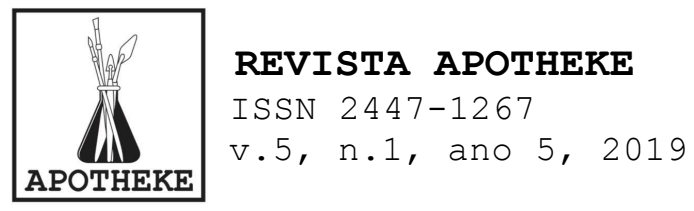

composição, é o vigor do traço o que prepondera. O que vemos na flor? Antes da imagem representada, vejo traço. o que vemos na palavra Venus? Antes da figura mitológica à qual a palavra remete, vejo traço. E nas linhas e rabiscos? Evidentemente, vejo o traço. Percebo, de maneira semelhante, as duas outras obras citadas acima, mesmo tendo conhecimento de que, para o artista, a sua temática, seu universo de referências está amalgamado com a sua prática e resultado visual. A descrição minuciosa apresentada por Claire Daigle (2012) 12 corrobora o sentido do processo de criação de Twombly:

\begin{abstract}
Em Venus o nome da deusa é gravado em um palimpsesto de linhas vermelhas com uma flor desenhada com bastão por baixo. Ela é acompanhada por uma lista de seus vários nomes feitos a lápis (Nadyomene, Aphrodite, Nymphaea...) e de suas associações (mirto, papoula, maçã, pardal...). 'Venus' é escrito de forma a enfatizar a abertura do ' $V$ ', ' $N$ ' e 'U'. No desenho pendente, 'Apollo' é delineado em azul escuro com um triângulo, o delta grego, servindo como a primeira inicial e dobrando como um ponteiro direcionado para cima. Como o delta, as duas letras 'o' do nome são formas fechadas, em oposição às cinco letras abertas de Venus. Apollo, também, é acompanhado por uma lista de seus vários nomes e atributos (louro, palmeira, falcão, gafanhoto...). Nesses desenhos, não é dada nenhuma definição direta (sem deusa do amor ou do deus da medida), mas sim uma rede de alusões dadas tanto a palavra quanto a forma. (DAIGLE, 2012).13
\end{abstract}

12 Escritora, historiadora e crítica de arte. Diretora do programa History and Theory of Contemporary Art - MA University of Massachusetts at Amherst.

13 Venus the name of the goddess is written out in a palimpsest of. red lines with a blossom drawn in crimson oil stick beneath. She is attended by a pencil-drawn list of her various names (Nadyomene, Aphrodite, Nymphaea...) and of her associations (myrtle, poppy, apple, sparrow...). 'Venus' is written out so as to emphasise the openness of the ' $V$ ', ' $N$ ' and ' $U$ '. In the pendant drawing, 'Apollo' is delineated in dark blue with a triangle, the Greek delta, serving as the first initial and doubling as a directional pointer upward. Like the delta, the two letters 'o' of the name are closed forms, as against the five open letters of Venus. Apollo, too, is accompanied by a list of his many names and attributes (laurel, palm, tree, hawk, grasshopper...). In these drawings, no direct definition is provided (no goddess of love or god of measure), but rather a network of allusions given both word and form. http://www.tate.org.uk/contextcomment/articles/lingering-threshold-between-word-and-image pesquisado em 22 julho de 2012 . 


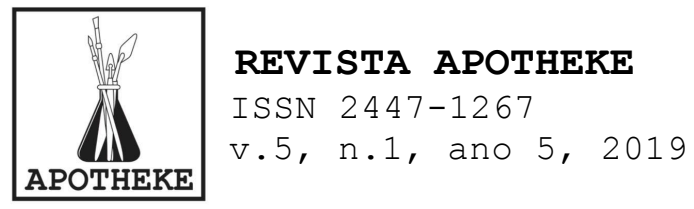

O comentário apresentado por Daigle aproxima-nos da provável maneira de Twombly articular tema, grafia, figura, desenho, pintura e escrita. A impressão que se tem é que, na equação que o artista estabelece entre os diversos elementos, ele foge de uma literalidade. Pode-se perceber um ruído dessas ligações, mas a ênfase sem dúvida está direcionada à construção de uma imagem potente. Barthes (1982, p.144), a esse respeito, apresenta um comentário no seguinte sentido: "uma tela de Twombly é somente o que se pode chamar de 'campo alusivo da escrita"". Barthes faz uso da palavra alusão no sentido de dizer "uma coisa com a intenção de fazer compreender outra". Twombly utiliza letras, palavras, alude à escrita, refere-se a esta, utiliza seus signos, mas muda de direção uma vez que foge dos padrões de uma boa caligrafia, do tipo de escrita que é desenhada e elaborada com esmero.

Twombly não faz uso da habilidade que se espera encontrar naquilo que é realizado com a mão direita. Por ser a escrita um elemento habitual nas obras de Cy Twombly, Barthes salienta em sua reflexão o fato de que a língua francesa, por ser essencialmente destra, considera que o que é feito de outro modo, com a mão esquerda, é canhestro, desajeitado, embaraçado. Barthes deduz daí que há também uma concepção moral e de julgamento para o que não é destro: o sinistro, o gauche, o que não serve, o que está fora do padrão aceito. Por essa via de pensamento, entende-se que Cy Twombly, ao produzir uma pintura gauche, "perturba a moral do corpo" (BARTHES, 1982, p.141), assimila a anomalia e a deficiência, o que o empurra para o grupo dos excluídos: crianças, velhos, enfermos... Assim, o canhoto seria uma espécie de cego que exerce a escrita sem enxergar. É justamente o que Twombly busca: desfazer o elo entre as mãos e os olhos. Seria como embaralhar a ordem desses procedimentos alcançando assim um desprendimento maior no uso da razão. 


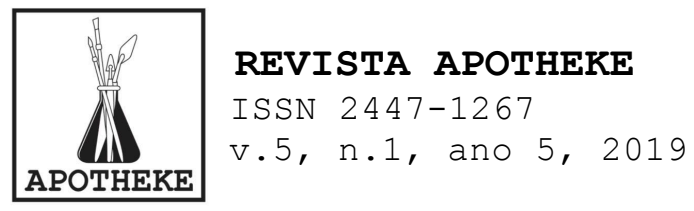

O universo da escrita, da caligrafia é uma constante na obra de Twombly. Ao utilizar a palavra em seus trabalhos, Twombly retém alguma camada de seu significado sem, no entanto, servir-se desta para construção de uma narrativa. O artista não esvazia o total sentido da palavra e, da mesma maneira que faz com as letras, trata-as como imagens na obra. Percebe-se também, na prática do artista, um deslizamento entre as categorias desenho e pintura; ele não estabelece uma comparação entre as duas modalidades como propõe Benjamin. O que se vê é um atravessamento entre estas. Twombly move-se nesse ambiente por vias de embaralhamento em que, da mancha, não obtém somente pintura, e com o traço, cria também campo de cor. Sua obra não polariza os meios dos quais se vale, não os estabiliza, deixa seus elementos em suspensão. Talvez resida aí a sua potência.

O estudo e a articulação dos pensamentos de teóricos que refletem sobre questões pertencentes ao âmbito das artes visuais constituem-se em instrumentos eficazes para a compreensão e fruição de obras artísticas. Várias são as instâncias de concepção de um trabalho artístico: conhecimento de história da arte e dos códigos da linguagem visual; o que está implicado na sua fatura; a participação de elementos conscientes e inconscientes do artista, racionais, emocionais e cognitivos; a habilidade manual e a relação do artista com seus materiais e conteúdos, entre outros. Apresentar a percepção de dois filósofos que distam 60 anos em suas considerações pode ser um exercício frutífero, visto que possibilita outros cruzamentos de ideias e novas articulações do pensamento. O conhecimento é formado por essas sinapses que nos permitem, de certa forma, atualizar nossa visão e compor novos sentidos.

\section{REFERÊNCIAS}




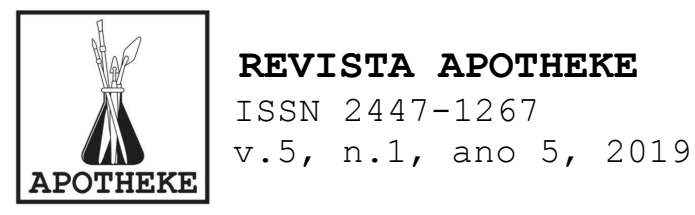

BARTHES, Roland. O óbvio e o Obtuso. Edições 70. Lisboa - Portugal, 1982.

BARTHES, Roland. A sabedoria da arte. Catálogo da $23 .{ }^{a}$ Bienal de São Paulo: Salas Especiais. São Paulo, 1996.

BENJAMIN, Walter. Sobre a Pintura ou Sinal e Mancha.Disponível em:

http://www.rae.com.pt/Caderno_wb_2010/Benjamin $\% 20$ Zeichen $\% 20$ und $\% 20$ Mal\%20port .pdf. Acesso em: 7 jun. 2012 .

DAIGLE, Claire. Lingering at the threshold between word and image - Cy

Twombly.Disponível em: http://www.tate.org.uk/context-

comment/articles/lingering-threshold-between-word-and-image. Acesso em: 22

jul. 2012 . 